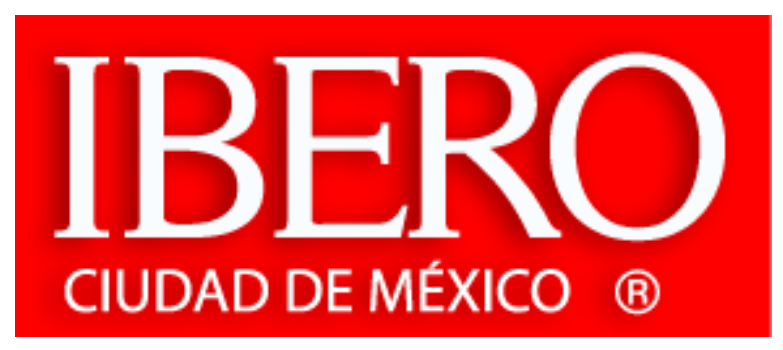

Departamento de Economía Serie documentos de trabajo 2013

\author{
Local Multipliers and the \\ Informal Sector in Mexico 2000-2010
}

\author{
Mariana Pereira-López \\ Isidro Soloaga
}

Agosto 2013

Documento de trabajo No. 5, 2013 


\title{
Local Multipliers and the Informal Sector in Mexico 2000- 2010
}

\begin{abstract}
This paper analyzes local multipliers and the relation between tradable job creation and informality in Mexico. Building upon local multipliers analysis, and taking into consideration agglomeration economies as well as general equilibrium effects, if finds that a new job in the tradable sector traduces into three new jobs in the nontradable sector. Half of these jobs occur in the informal sector, which is not a desirable outcome considering the low tax collection and vulnerability to labor market shocks associated to informality. Considering the skill composition of the tradable sector, individuals with some college or more have a much higher multiplier over nontradable jobs compared to other skill levels. There are asymmetric effects in terms of the multiplier as negative shocks (job losses) have higher effects.
\end{abstract}

Key words: local multipliers, informal sector, agglomeration, pecuniary externalities, Mexico JEL classification: J23, R11, R12, R23

Mariana Pereira-López (marianappl@gmail.com)

Isidro Soloaga (isidro.soloaga@ibero.mx)

Universidad Iberoamericana Ciudad de México

August, 2013 


\section{Local Multipliers and the Informal Sector in Mexico 2000-2010}

\section{Introduction}

Every time new jobs are created, they have further effects in the economy due to the fact that newly employed individuals increase their expenditure and thus, stimulate other industries. That is why these so called multiplier effects are taken into account in the evaluation of economic crises recovery plans (See Romer \& Bernstein 2009).

As Moretti (2010) argues, this same process occurs at the local level when new businesses are attracted, increasing local demand for goods and services; even though this indirect job generation is partially offset by general equilibrium effects induced by local wages and nontradable prices increases. ${ }^{1}$ The value of this multiplier is important for regional development and for public policy, as local governments grant incentives for firms to locate in a given city and the knowledge of these figures can help to better target these efforts or gauge its appropriateness. Additionally, as this same author notes, local multipliers provide bounds for national multipliers.

Considering the negative case, as Black, McKinnish and Sanders (2005) mention, when a firm closes there is concern regarding expected jobs losses. Therefore it is important to have a measure of indirect jobs created (or lost), which according to Moretti and Thulin (2013) has a great variation across industries and types of jobs.In the case of the U.S., the results obtained by Moretti (2010) indicate that whenever a job is created in the tradable sector 1.6 nontradablejobs arise, but a much higher multiplier is observed when only skilled jobs are considered.

In the case of a developing country, such as Mexico, it is not only important to assess the magnitude of the multipliers, but the quality of this indirect job creation, as informality is a widely observed phenomenon in this kind of countries and, as Maloney (2004) argues, most of it occurs in the nontradable sector. According to Mexico's National Institute of Statistics and Geography (INEGI), more than $60 \%$ of national employment belongs to the informal sector. Informal jobs represent a lower tax collection and more expenses (e.g. the Seguro Popular in the case of Mexico, which grants medical insurance for informal and unemployed individuals) on the government's side, while on the workers' side it represents concerns regarding job security, as

\footnotetext{
${ }^{1}$ In most theoretical models based on Rosen (1979) and Roback (1982) these nontradable prices are mainly housing prices as this sector is included along with firms and consumers (workers).
} 
well as a higher vulnerability to labor market shocks. As Loayza and Sugawara (2005) point out, informality is not only a sign of underdevelopment but may be the source of further retardation. ${ }^{2}$

This paper estimates the local multiplier for Metropolitan Areas (MAs) in Mexico between 2000 and 2010; that is, nontradable jobs created as a result of new tradable jobs.Furthermore, it assesses whether indirect creation of employment is focused on the formal or the informal sector. In this sense, its main contribution and departure from previous literature is to analyze informality in the framework of the local labor markets literature, which allows assessing the quality of local job creation.It also analyzes the role of skilled and unskilled tradable jobs in this process as well as the effects by technological intensity.

In order to correctly identify these effects, the ideal experiment would be to have two otherwise similar cities and compare jobs creation after the establishment of a new tradable firm in one of them. However, as commonly observed in non-experimental empirical analysis, the problem with these multipliers' estimation isthat there is no counterfactual to whether the firms decided to locate elsewhere.Hence, it is difficult to assess whether nontradable employment grew in a region as a consequence of this new firm or if nontradable employment would have grown anyway. Therefore, as Delgado, Porter and Stern (2005) argue it is important to account for convergence (or divergence) in these empirical exercises. Additionally, in order to address the problems generated by unobserved shocks to nontradable employment that also affect tradable employment, an instrumental variables (IV) approach is used.

The paper is organized as follows: section 2 presents the conceptual framework that supports the predictions of local multipliers.Section 3 provides a literature review of both theoretical and empirical studies on local multipliers as well as on articles regarding informality. In section 4 , the methodology is presented. Section 5 explains the data used in the analysis as well as some descriptive statistics. Results are discussed in section 6 and conclusions in section 7.

\section{Conceptual framework}

\subsection{Local multipliers}

Following Moretti (2010), Moretti (2011) and Moretti and Thulin (2013) and starting from the Rosen-Roback spatial equilibrium model, which is regarded by Glaeser (2009) as the

\footnotetext{
${ }^{2}$ In their empirical analysis these authors find negative effects of informality on economic growth.
} 
workhorse of spatial economics, it is assumed that each locality is a competitive economy that produces nationally traded goods, which prices (considered as a numeraire) can't be affected locally; as well as nontradable products, which prices are determined locally. Labor is perfectly mobile across sectors within a city. Therefore, marginal product equals wages within the locality.

In general, these models use the Cobb-Douglas specific functional form for the production function. It is also common to assume that workers are heterogeneous, considering skilled and unskilled workers. ${ }^{3}$ The first group of workers is expected to receive higher wages $\left(w_{s} \geq w_{u}\right)$.

On the workers' side, their utility function depends on their wages less their housing and consumption expenses. Moretti (2011) includes idiosyncratic preferences for location in order to have an upward sloping labor supply against the standard model in which labor mobility is perfect and supply is infinitely elastic. ${ }^{4}$

The sector that closes the model is housing, or the nontradable sector in models such as Glaeser and Gottlieb (2009), which is assumed to have an upward sloping supply.

All of these models predict that when an exogenous variable impacts traded goods productivity, such as the establishment of a new firm, the number of workers in the city increases, as well as wages and housing prices.

In the case of the tradable sector, which price is not determined locally, it is not clear whether it generates other jobs besides the ones directly associated with the shock, because it depends on general equilibrium effects, as well as on the linkages between the different industries that compose this sector. First, as predicted by the model, wages rise, generating a cost increase for other tradable firms that cannot be compensated through prices increases. Therefore, employment in other parts of the tradable sector may experience reductions, due to the loss of competitiveness. Second, if traded industries have strong backward and forward linkages or agglomeration economies are important, it is possible that the demand shock generates an increasing demand for intermediate goods and thus a positive multiplier of tradable goods over other tradable goods. In the case of agglomeration economies, as Greenstone, Hornbeck and Moretti (2010) show, the demand shock could enhance agglomerations.

\footnotetext{
${ }^{3}$ In this kind of models, imperfect substitution between skilled and unskilled workers can be included as an assumption.

${ }^{4}$ This assumption is related to the spatial equilibrium assumption, which requires utility to be equalized across locations. As Moretti and Thulin (2013) mention, including idiosyncratic preferences about location generates more realistic equilibrium conditions, as utility needs not to be the same for all individuals in all locations, it is just equalized for marginal workers and not for inframarginal.
} 
For the nontradable sector, which is the most interesting analysis because, as Glaeser (2008) points out, cities are increasingly oriented around this sector, particularly in the case of business services, requiring a higher level of interaction with other people, as the city has more workers with higher wages, the demand for nontradable goods (mainly services such as restaurants, medical services, dry-cleaning, haircuts, etc.) increases.

As Moretti (2010) explains, the magnitude of these effects depends on several factors. First, consumer preferences regarding nontradable products; if consumers (workers) have strong preferences for nontradable goods the multiplier will take a higher value. Second, tradable goods production technology; if the demand shock occurs in a sector that is labor intensive, the direct effect on the number of workers will be higher and, thus, their demand for nontradables will be higher, resulting in a larger multiplier. Third, the type of new jobs; as mentioned before, skilled workers receive higher wages, so if the share of skilled workers is higher in the industry in which the demand shock occurs, a larger multiplier is expected. Finally, general equilibrium effects on wages and local housing prices could partially offset the positive effect on nontradable products; as wages increase, local services costs are also higher, generating a decline in the supply of services (a partial crowding out on the nontradable sector) that also depends on labor supply elasticity.

Regarding the relation of these local multipliers with the national multipliers that as Moretti (2010) argues are crucial elements in countercyclical stimulus policies, this author mentions that tradable multipliers are a lower bound for national multipliers while nontradable multipliers can be interpreted as the upper bound.

\subsection{Informal sector models}

Even though informality models vary in their assumptions, their predictions regarding the effects of demand shocks in the tradable (mostly formal) sector on informality are similar. As will be explained in more detail later, there are two opposing lines of research regarding the causes of informality, one that considers that it arises from a segmented market, and a second that assumes that it consists of a voluntary decision in the context of integrated markets. ${ }^{5}$

Under the theoretical strand that considers a segmented market, Rauch (1991) constructs a model based on the concepts of labor market dualism and size dualism in which there is a

\footnotetext{
${ }^{5}$ See Esquivel and Ordaz-Díaz (2008) for a discussion regarding these two theoretical approaches.
} 
minimum wage that is only enforced for firms with a certain size (formal). The size of the firms is based on the distribution of entrepreneurs' talent or managerial skills. The model's assumptions result in an endogenous choice between the formal and the informal sector. In this framework, increases in the formal sector wage, such as the ones induced by tradable demand shocks or efficiency wages, result in increases in the differential between formal and informal wages. ${ }^{6}$ This higher differential causes a higher supply of workers seeking the higher formal wages, as well as a lower labor demand in the formal sector and thus, increases the size of the informal sector. Considering the higher demand for nontradable products, depending on entrepreneurs' skills (determinant of firms' size), some of the firms responding to this demand will be informal. Therefore, a higher proportion of untalented managers will increase the size of the informal sector. Fortin, Marceu and Savard (1997) generalize this model by including taxes besides minimum wages and assuming a cost function for informal firms, which is directly related to the risk of being caught in tax evasion and not complying with minimum wages. Under these assumptions a demand shock in the tradable sector that increases wages, may force small formal firms (either tradable or nontradable) to go into the informal sector due to the higher labor costs.

Models such as Straub (2005) go further on the firms' perspective. In particular, this model analyzes the decision of being formal or informal in an investment framework with credit constraints, moral hazard and entry costs into formality. The model assumes that it is possible to verify the results of an investment project in the case of formal firms, ensuring repayment, while it is not possible to do so for informal firms, so lenders end up using coercion mechanisms to avoid default. Under this kind of model, the response of informality to demand shocks depends on the efficiency of credit markets as small firms seeking to take advantage of the higher nontradable demand may prefer becoming informal to avoid entry costs and because they face credit rationing.

Finally, considering the line of research that starts from an integrated labor market, where individuals optimally decide whether to work in the informal sector or in the formal sector, under a life-cycle framework just as the one mentioned in Maloney (2004), the increase in wages generated by the demand shock in the tradable sector, provides incentives (capital) for employees

\footnotetext{
${ }^{6}$ Under this approach, for similar individuals, wages in the formal sector are higher than the ones of the informal sector.
} 
to become entrepreneurs and move to the informal sector. Also, as Levy (2008) argues, under this strand of the literature, social programs focused on the informal sector, such as Seguro Popular in the case of Mexico, may create perverse incentives for formal workers to become informal. $^{7}$

As will be explained in the following section, empirical studies have found mixed results. However, recent studies for Mexico tend to support the view of a segmented market.

\section{Literature Review}

\subsection{Local multipliers}

The analysis of local multipliers builds upon spatial labor markets equilibrium analysis. As Glaeser (2008) mentions, the most important concept in regional economics is the spatial equilibrium condition that indicates that if two identical individuals choose different locations it must be because they are receiving the same level of utility. That is, if an individual chooses a location with low wages it must be because he is being compensated with something else (amenities or another advantage).

Starting from this crucial assumption, standard spatial equilibrium models, such as the ones presented by Glaeser and Gottlieb (2009) and Moretti (2010), predict that followinga local demand shock in the tradable sector (e.g. the attraction of a new firm), the number of workers and wages in a city will increase. Thus, apart from the tradable jobs directly created, a set of nontradable jobs will arise as a result of the increasing demand for these products, mainly services. The magnitude of this multiplier effect, as already explained in section 2,depends on different factors such as consumer preferences, technologies, and skill levels.

As Black et al. (2005) argue, there are two different strands of literature in the empirical analysis of local multipliers or the effects of demand shocks on employment. The first one estimates local effects using aggregated labor data, and the second one takes advantage of specific and localized labor shocks to identify their effects. An example of this first approach is Moretti (2010) who uses U.S. Census data from 1980 to 2000 and estimates a long-term local

\footnotetext{
${ }^{7}$ It is important to note that under this framework, the same individual will receive a higher wage in the informal sector.
} 
labor multiplier of 1.6 for the whole sample, finding significantly higher effects (2.5) for tradable skilled jobs. A similar analysis is performed by Moretti and Thulin (2013) with a matched employer-employed database for Sweden finding a multiplier of tradable jobs over nontradable ranging between 0.4 and $0.8 .^{8}$

Along the second line of research are papers such as Carrington (1996), who uses the specific shock generated by the construction of the Trans-Alaskan Pipeline Systembetween 1974 and 1977 to analyze the employment dynamics in that state. As Black et al. (2005) notes, this was a very large temporary shock into a very small economy (Alaska). Additionally, due to its climate, Alaska experiences swings in its employment and population, which could have generated a smoother pattern in terms of employment, against what might be observed in other states. That is, though significant effects were found, the results for Alaska may have a lot of particularities that make it difficult to draw general conclusions from it.

Following this same strand, Black et al. (2005) take advantage of the coal boom in the 1970s during the OPEC oil embargo, and the later coal bust during the 1980s. These authors find that the effects of new employment in the mining sectors on local jobs was of 0.17 , while the negative effect (job losses) due to the coal bust was of 0.35 . These results indicate asymmetry in the effects as negative demand shocks have an effect of almost double than positive shocks. Effects on the tradable sector were not significant.

Moretti and Greenstone (2004) take a totally different approach by using information of "Million Dollar Plants" articles of the corporate real estate journal Site Selection, which describes the location process of new plants in U.S. counties. The main advantage of this dataset is that it allows them to construct a counterfactual by comparing the winner counties with runner-up counties. Even though they conclude that their estimates are imprecise, they find employment effects for industries in different sectors from the incumbent, as well as for neighbor counties.

\footnotetext{
${ }^{8}$ In the case of Moretti and Thulin (2013) Stockholm proves to be an influential observation as once it is included in the sample, this multiplier increases, taking a value of approximately four nontradable jobs for each tradable job created.
} 


\subsection{Informal economy}

The informal economy is a phenomenon observed mainly in developing countries. ${ }^{9}$ A great deal of research has been conducted in order to assess the causes of informality, but there is still no consensus on its causes, let alone its definition and measurement. In the case of Mexico, for example, the measurement of informality was adjusted recently according to the International Labor Organization (ILO) statistical manual, changing the informality rate from $34 \%$ to $60 \% .^{10}$

Regarding the definition of informality, as Fortin et al. (1997) mention, in general, three approaches have been used to distinguish the informal sector from the formal under the segmented market or dualism line of research. The first one is the scale of the firm, measured by its number of workers. Under this approach, which these authors call scale dualism, an arbitrary threshold is defined and firms smaller than it are considered informal. The second, regarded as wage dualism, considers the wage differential between identical individuals. Such a segmentationcan arise from market rigidities and regulations. The third view, referred to as evasion dualism, consists on those firms that avoid paying taxes and other contributions, mainly social security.

Considering its causes, as Rauch (1991) argues, initially this sector was not even seen as a topic worth of separate study. In the Harris-Todaroframework ${ }^{11}$ it was seen as consequence of segmented or dualistic labor markets, as a temporary stage in the process of migration, where unskilled rural workers that migrated to urban environments were waiting to be absorbed by a modern formal sector, obtaining thus a more permanent job.

Other recent studies under this framework focus on the firms' side more than the employment side. For example, Straub (2005) emphasizes credit market rigidities. These models are closely related with occupational choice models following Banerjee and Newman (1993), where the lack of access to credit markets that stems from moral hazard, prevents some agents from becoming entrepreneurs.

A related literature, as mentioned in Loayza and Sugawara (2005), considers that the presence of a burdensome regulatory framework, with bad quality in public services and weak

\footnotetext{
${ }^{9}$ According to Bonner and Spooner (2011), the informal sector represents between 50 percent and 75 percent of nonagricultural employment in developing countries. Although there are not comparable statistics for developed countries, these authors argue that approximately $25 \%$ of employment in the U.S is non-standard or atypical (selfemployment, part-time work or temporary work) which, though not all of them are informal, most of them receive little if any employment benefits.

${ }^{10}$ See INEGI (2012) and ILO (2012)

${ }^{11}$ See Ray (1998) for a summary and predictions of this model.
} 
law enforcement, generates incentives for firms, specially the small ones, to operate in the informal sector.

However, contrary to the theoretical predictions of segmented market models, as both Rauch (1991) and Maloney (2004) argue, reverse mobility has been observed with formal sector workers changing into the informal sector, challenging this view. Therefore, other lines of research have been developed seeking to explain these movements.

A recent variant of the dualistic view, according to Maloney (2004), is the one that considers that informality is caused by firms facing international competition (price takers) who due to high labor costs induced by wage rigidities, decide to subcontract informal workers at a lower wage. However, in the case of Mexico, this same author reports that only $20 \%$ of informal selfemployed firms report being affiliated to larger firms.

As Esquivel and Ordaz-Díaz (2008) argue,there is mixed empirical evidence for Mexico regarding whether there areintegrated markets (with a wage premium in favor of the informal sector) or segmented markets (with a wage premium in the formal sector).

In favor of integrated markets, Maloney (2004) argues thatin the case of Mexico, wage rigidities that would lead to a segmented labor market are not observed and more than $60 \%$ of self-employed individuals in the informal sector left their previous formal jobs and entered informality voluntarily.Therefore, this author considers the alternative theory of a life-cycle model where workers enter into the formal sector, acquire certain abilities and knowledge, as well as capital and contacts, and then leave in order to open informal own businesses. He also argues that the later entry into informality is also consistent with a safety net where older people who become unemployed are unable, due to the obsolescence of their abilities, to re-enter the formal sector and thus, end up entering informality. Additionally, informal jobs offer less demanding work for this group. Something similar happens in the case of married women, who can more easily balance work and homecare working for themselves than in formal employment. Considering this attractiveness of the informal sector, formal employers must generate incentives (wage premium) for their employees not to leave their jobs to enter informality. That is, under this hypothesis, informality generates dualistic markets and not the other way around. Perry et al. (2007) also obtain results consistent with integrated labor markets for Mexico.

Recent studies for Mexico, such as Arias, Azuara, Bernal, Heckman, and Villareal (2010) find evidence that support the hypothesis of segmented markets. According to these authors, 
informality in Mexico is primarily caused by regulation and levels of taxation. By analyzing the trends of informality rates, they conclude that the beginning of Seguro Popular did not change the previous trend, contrary to what the integrated markets hypothesis would predict. Esquivel and Ordaz-Díaz (2008) analyze whether social programs really generate incentives for informality in Mexico, as Levy (2008) argues. Their results show that there is a wage premium in Mexico's formal labor market, which is consistent with the hypothesis of a segmented market. Alcaraz, Chiquiar and Ramos-Francia (2008) obtain similar results in favor of the dualistic hypothesis.

As the empirical evidence shows, there is no agreement regarding the causes of informality. Perry et al. (2007) even allow for the possibility of the two hypothesis coexisting in the same labor market.

Even though consensus hasn't been reached on the causes of informality, according to Galiani and Weinschelbaum (2012), three stylized facts characterize the informal sector. First, small firms tend to be informal while larger firms are usually formal (scale dualism). Second, as Loayza and Sugawara (2005) also argue, the wage gap between the formal and the informal sector is larger for skilled people, making the informal sector a last resort for this kind of people, while for unskilled people it appears to be a first choice. Finally, family members different from the household head have a higher probability of entering the informal sector; this last statement is based on the idea that having one member of the family (usually the head) working in the formal sector provides medical insurance and other benefits for all the other members; this allows them to make riskier choices such as entering the informal sector.

\section{Empirical strategy}

Following Moretti and Thulin (2013) the following equation is estimated:

$$
N_{c, t}^{N T}-N_{c, t-s}^{N T}=\alpha+\beta N_{c, t-s}^{N T}+\gamma\left(N_{c, t}^{T}-N_{c, t-s}^{T}\right)+\varepsilon_{c, t}(4.1)
$$

Where

$N_{c, t}^{N T}=$ Employment in the nontradable sector in city $c$ at time $t$

$N_{c, t-s}^{N T}=$ Employment in the nontradable sector in city $c$ at time $t-s$

$N_{c, t}^{T}=$ Employment in the tradable sector in city $c$ at time $t$

$N_{c, t-s}^{T}=$ Employment in the tradable sector in city $c$ at time $t-s$ 
Even though this expression in logarithms, as used in Moretti (2010) yields similar results, the main advantage of this formulation is that the parameter $\gamma$ gives directly the value of the multiplier, without the need of multiplying the ratio of nontradable employment over tradable to calculate itfrom the elasticity.

It is important to note that following Delgado, Porter, and Stern (2005), as well as the growth literature, unlike previous analysis of local multipliers, the initial level of nontradable employment is included in order to control for convergence.Thus, $\beta$ stands for the convergence parameter of standard growth equations.

Variants of equation 4.1 are estimated, in order to assess the effects of skilled-unskilled tradable employment, of formal-informal tradable employment and different technological intensity groups. In a departure from previous literature and considering the particularities of a developing country such as Mexico, on the left-hand side of the equation, the effects are analyzed for the formal and informal sectors.

In order to assess the effect of tradable employment shocks on other tradable sectors, as Moretti (2010) and Moretti and Thulin (2013) do, we estimate the following equation:

$$
N_{c, t}^{T 1}-N_{c, t-s}^{T 1}=\alpha^{\prime}+\beta^{\prime} N_{c, t-s}^{T 1}+\gamma^{\prime}\left(N_{c, t}^{T 2}-N_{c, t-s}^{T 2}\right)+\varepsilon_{c, t}
$$

Where:

$\Delta N_{c t}^{T 1}=$ Randomly selected part of the tradable sector.

$\Delta N_{c t}^{T 2}=$ Rest of the tradable sector.

In the simple model of Moretti (2010) it is expected that $\gamma>\gamma^{\prime}$ due to the increase in labor costs as a result of the demand shock. As Black et al. (2005) argue, firms that trade their goods nationally (price takers) do not necessarily face a higher demand for their products, but wage increases affect them as well. Thus, this increase in costs may even reduce their employment, causing an employment crowding out in the tradable sector. In this case, the local multiplier on tradable goods could even be negative (depending on local supply elasticity), reflecting this crowding out effect. On the other hand, this multiplier could be positive in the case of significant agglomeration economies or vertical integration in the framework of local supply chains. ${ }^{12}$ Then, the value of the tradable multiplier that we observe is the combination of these two opposite forces.

\footnotetext{
${ }^{12}$ This could be the case of perishable tradable products that tend to have local suppliers.
} 


\subsection{Instrumental variables}

As Moretti (2010) and Moretti and Thulin (2013) mention, if there are unobserved shocks tonontradable employment that also affect tradable employment, OLS estimators become inconsistent. An example of this kind of shocks could be local labor supply shocks. In order to address these problems, in both articles, IVs are used. The idea is to construct a shift-share instrument that considers demand shifts in a sector out of the city and weights them by city employment in that sector in the initial period (in this case 2000). This instrument was calculated using 22 three-digits NAICS industries:

$$
I V=\sum_{j}^{J=22} N_{c, j, t-s}^{T}\left(\ln \left(N_{j, t}^{T}-N_{c, j, t}^{T}\right)-\ln \left(N_{j, t-s}^{T}-N_{c, j, t-s}^{T}\right)\right)
$$

Where

$N_{c j, t}^{T}=$ Employment in the tradable sector in city $c$, sector $j$, at time $t$

$N_{j, t}^{T}=$ National employment in the tradable sector in sector $j$, at time $t$

Group specific instruments were calculated for the different variants of equation 4.1. For some of these specific instruments, the hypothesis of weak instruments couldn't be rejected; we indicate whenever this is the case so results are interpreted with caution. ${ }^{13}$ Therefore, the possibility that the relation between the instrument and the exogenous variable is non-linear was also considered in all cases and another instrumental variable (IV2), which includes a quadratic term, was also used.

\section{Data and descriptive statistics}

\subsection{Data sources and sample characteristics}

The data used in this paper come from microdata of the 2000 and 2010 Population and Housing Censuses' samples. These data were used instead of Economic Census data as it includes information regarding whether an individual works in the informal sector. ${ }^{14}$ However, as the primary objective of this census is not employment but demographic characteristics of the

\footnotetext{
${ }^{13}$ As Moretti (2010) notes an empirical problem experienced in this kinds of analysis is that IV estimates are not identified for all groups.

${ }^{14}$ The 1990 Population and Housing Census was also taken into consideration but we weren't able to use it in the analysis as it does not include the variables necessary to classify employment as formal or informal.
} 
population, the quality of the data was assessed by comparing it with the information obtained for the closest Economic Census. For both periods of analysis the correlation between employment in the Population and Housing Census and the same variable of the Economic Census was $0.96 .^{15}$

As the analysis is focused on employment, the sample includes individuals aged 18-66 who live in any of the 58 MAs considered. ${ }^{16} \mathrm{MAs}$ are used as the unit of analysis becausein theory, they are the administrative regions closest to local labor markets. Considering municipalities instead of MAs, although it would have provided us with more degrees of freedom, commuting between municipalities, which is likely to occur, can bias the analysis.

Skilled people in the sample are defined as those individuals with nine or more years of schooling. ${ }^{17}$ Even though it is clear that within the human capital literature an individual with this level of schooling cannot be considered a skilled worker, this definition was used taking into consideration Mexico's educational structure. Thus, an alternative definition (some college or more) was used in order to compare results.

\subsection{Tradable and nontradable sectors}

As Moretti and Thulin (2013) mention, there are different approaches to determine the tradability of each sector. In this case, two-digit NAICS sectors were classified according to the tradability analysis performed by Spence and Hlatshwayo (2011) for the U.S. Those sectors that exhibited more than $80 \%$ of tradability for that country are considered tradable. That is, we are using a classification that is exogenous to our data. The methodology used by these two authors is based on Jensen, Kletzer, Bernstein, and Feenstra (2005) and they use concentration indexes, considering that tradable sectors tend to be more regionally concentrated as they don't require much interaction with the final consumers. In this sense, these authors use the Ellison and

\footnotetext{
${ }^{15}$ The 2010 Housing and Population Census was compared with the 2009 Economic Census while the 2000 Housing and Population Census was compared with the 1999 Economic Census.

${ }^{16}$ The $58 \mathrm{MA}$ are constructed using CONAPO and INEGI's definition. Three additional MAs are included because of the importance of the maquiladora industry and the industrial growth of these areas. See Appendix I for the construction of the MAs.

${ }^{17}$ This is a conventional definition of skilled in the case of Mexico. For example, it is one of the definitions used by Cortez (2001) in his analysis of wage inequality for Mexico.
} 
Glaeser (1997) concentration index and the Gini coefficient. ${ }^{18}$ Spence and Hlatshwayo (2011) add robustness to this methodology by including the analysis of imports and exports as determinants of tradability.

Following Delgado et al. (2005) we exclude natural resource-dependent sectors, as these authors consider them as a different group besides tradable and nontradable and, due to their particular characteristics, they shouldn't respond in the same way than nontradable products to tradable demand shocks.

This methodology basically led to the same results as the traditional or, as called by Moretti and Thulin (2013) assumption methodology, which regards mainly the manufacturing sector as tradable and the services sector as nontradable. In order to test whether this classification really applies for Mexico, an analysis of two-digits and three-digits NAICS sectors was performed using the Census dataset. In this case, the threshold commonly used for the U.S. (0.3 in Porter, 2003) does not apply as the different sectors show a much higher concentration (inequality) in employment. The median-average Gini coefficient for these sectors is of 0.71 in an analysis excluding Valle de Mexico. All of the manufacturing sectors have Gini indexes above the median and seven out of the ten highest indexes in the three-digits analysis correspond to this sector. These results indicate that the classification between tradable and nontradable sectors is correct.

Another approach for the classification of products between tradable and nontradable (not used here) is the use of location quotients (LQ), which basically compare the employment share of certain sector in a city with its share in national employment. ${ }^{19}$ In general, the Gini coefficient and LQs are used together (See Delgado et al., 2005) in order to obtain more robust classifications.

\subsection{The informal sector}

The informal sector definition is based on the ILO's statistical manual and INEGI's technical note regarding the new methodology for measuring informality. The informal sector

\footnotetext{
${ }^{18}$ As Spence and Hlatshwayo (2011) point out, the classification in Jensenet al. (2005) works better for domestic markets than for international markets.

${ }^{19}$ The LQ has the same specification as the specialization index used in Glaeser et al. (1992).
} 
includes workers with no access to social security (medical services), household paid domestic services, independent workers and non-paid family work. ${ }^{20}$

\subsection{Descriptive statistics}

Table 1 shows the sample's composition of employment between tradable and nontradable sectors for 2000 and 2010. During this period, the share of the tradable sector reduced from $25 \%$ to $20 \%$ for the whole sample. The pattern is similar when only MAs are considered.

TABLE 1. TRADABLE VS. NONTRADABLE SHARES IN TOTAL EMPLOYMENT 2000-2010

\begin{tabular}{|c|c|c|c|c|}
\hline & \multicolumn{2}{|c|}{2000} & \multicolumn{2}{|c|}{2010} \\
\hline & Number & $(\%)$ & Number & $(\%)$ \\
\hline \multicolumn{5}{|l|}{ National sample } \\
\hline Tradable employment & $5,982,509$ & $25 \%$ & $6,108,240$ & $20 \%$ \\
\hline Nontradable employment & $17,521,152$ & $75 \%$ & $24,351,842$ & $80 \%$ \\
\hline Total & $23,503,661$ & $100 \%$ & $30,460,082$ & $100 \%$ \\
\hline Only MAs & Number & $(\%)$ & Number & $(\%)$ \\
\hline Tradable employment & $4,298,245$ & $27 \%$ & $4,248,513$ & $21 \%$ \\
\hline Nontradable employment & $11,744,621$ & $73 \%$ & $15,983,348$ & $79 \%$ \\
\hline Total & $16,042,866$ & $100 \%$ & $20,231,861$ & $100 \%$ \\
\hline
\end{tabular}

Source: Author's calculations using data from the Mexican Population and Household Censuses for 2000 and 2010. The sample includes employed individuals aged 25-66.

Figure 1 shows the correlation between tradable employment growth and nontradable employment growth in the period of analysis. As can be seen in the figure, there appears to be a direct relation between these two variables, consistent with the theoretical model. An interesting

\footnotetext{
${ }^{20}$ See INEGI (2012) and ILO (2012). Results using alternative definitions of informality, which analyzed different labor benefits such as pension funds, Christmas bonuses and paid vacations, were also considered, obtaining similar results.
} 
feature observed in this graph is the relative importance of Valle de Mexico in terms of nontradable employment, which concentrated more than $30 \%$ of tradable MAs employment and more than $35 \%$ of nontradable MAs employment in 2000. Not only is this area important in terms of its weight in total employment, but it also showsdifferent dynamics than most of the other MAs, as its growth rates for tradable and nontradable employment are much lower (even negative for tradable employment). These figures are consistent with the process of decentralization that especially the industrial sector has experienced since the mid-1990s. These data also indicate that this MA could be an influential observation, so results including it must be analyzed with caution. That is why, estimates of equation 4.1 are calculated both including and excluding this MA and results are compared.

Growth rates for other MAs with high levels of nontradable employment in 2000 show that most of them experienced rates above the mean for nontradable employment, but below the mean for the tradable sectors. These growth patterns are an indicator of the increasing role of the services sector in these large MAs.

FIGURE 1. EMPLOYMENT GROWTH IN THE TRADABLE SECTOR VS. EMPLOYMENT GROWTH IN THE NONTRADABLE SECTOR 2000-2010

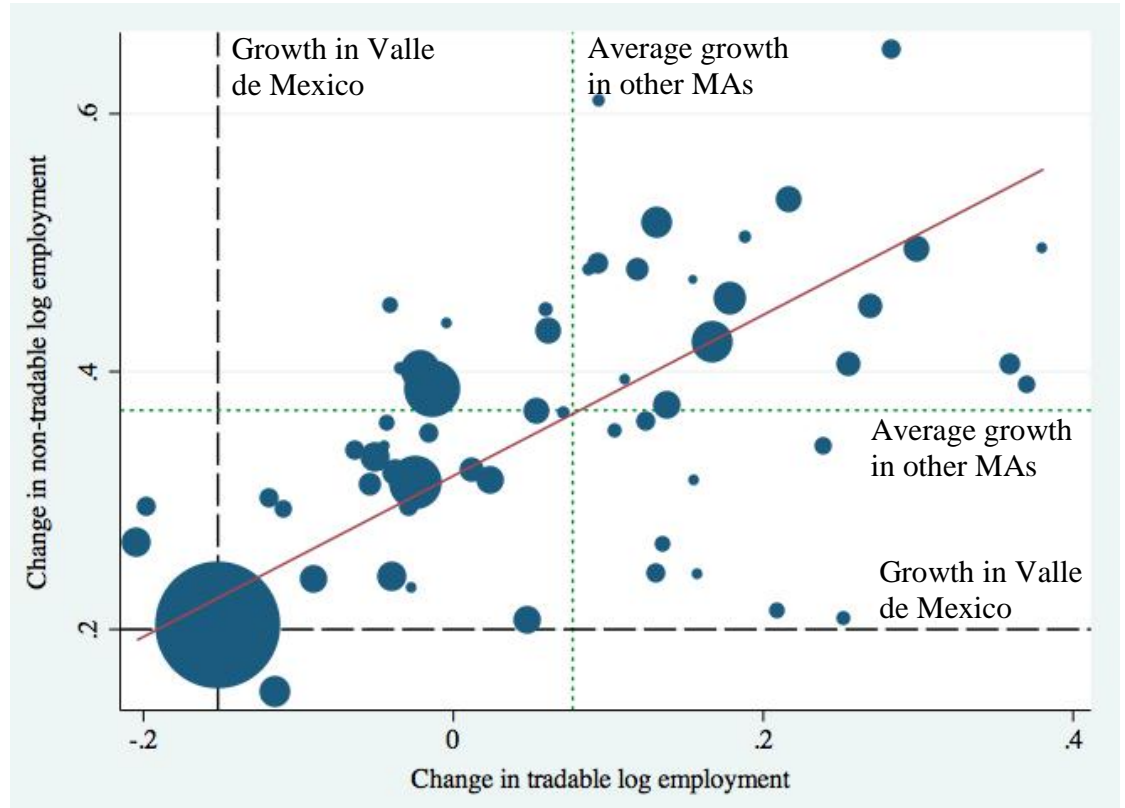

Source: Author's calculations with microdata from the 2000 and 2010 Housing and Population Censuses' samples. The markers' size reflects nontradable employment in 2000. 
Analyzing informality by MA, as Figure 2 shows, this issue has clear regional patterns. As can be seen in the first panel, the northern region of the country was the one that exhibited the lowest rates of informality in 2000, while the central-south region is where informality was stronger. As the second panel shows, this pattern didn't change much by 2010 , even though some MAs in the northern region increased their informality rates. Only five MAs out of the 58 analyzed showed reductions in their informality rates during this period and all of them are concentrated in the Gulf of Mexico and the Yucatan Peninsula.

FIGURE 2. INFORMALITY RATES BY MA 2000-2010

2000

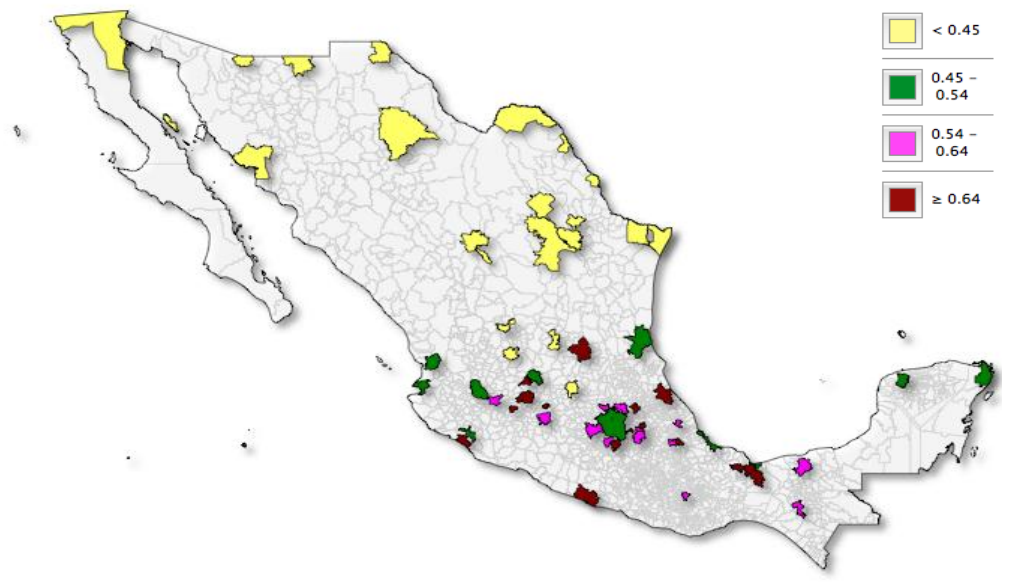

2010

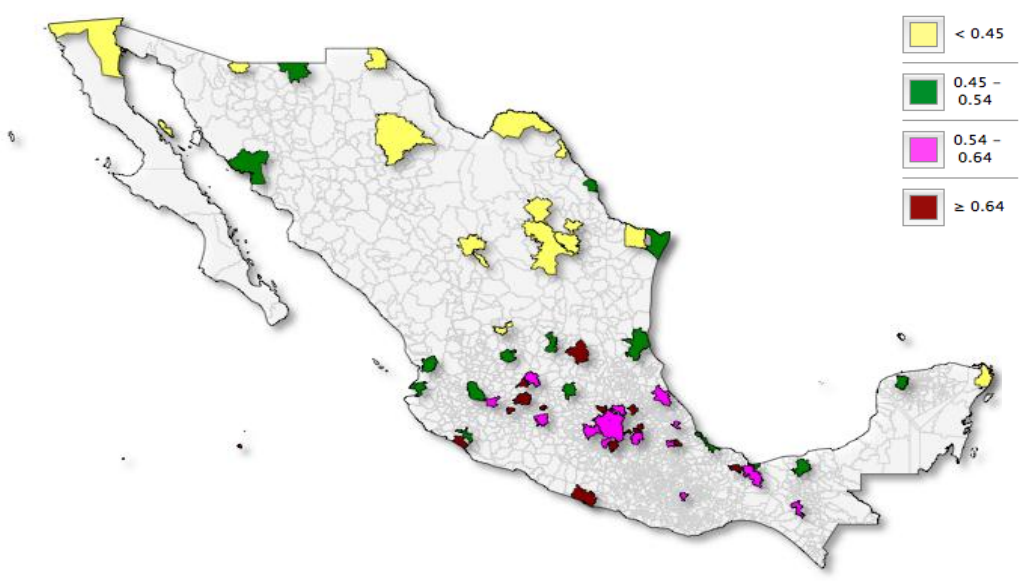

Source: Author's calculations with microdata from the 2000 and 2010 Housing and Population Censuses'samples.

As can be seen in Table 2, in 2000 the nontradable sector had a much higher average informality rate $(59 \%)$ than the tradable sector $(32 \%)$. Both rates are very stable as in the last ten 
years the first one did not change and the second one increased in just three percentage points, reaching $35 \%$ in 2010 .

TABLE 2. MAS EMPLOYMENT INFORMALITY STRUCTURE AND SKILLS STRUCTURE IN THE TRADABLE AND NONTRADABLE SECTORS

2000-2010

\begin{tabular}{|c|c|c|c|c|}
\hline & \multicolumn{2}{|c|}{2000} & \multicolumn{2}{|c|}{2010} \\
\hline & Nontradable & Tradable & Nontradable & Tradable \\
\hline Formal & $4,567,118$ & $2,784,012$ & $6,131,753$ & $2,638,589$ \\
\hline Informal & $6,475,287$ & $1,306,305$ & $8,941,574$ & $1,412,252$ \\
\hline Informality rate & $59 \%$ & $32 \%$ & $59 \%$ & $35 \%$ \\
\hline Unskilled & $4,401,159$ & $1,619,448$ & $4,407,639$ & $1,124,271$ \\
\hline Skilled & $7,343,462$ & $2,678,797$ & $11,575,709$ & $3,124,242$ \\
\hline Skill rate $*$ & $62.5 \%$ & $62.3 \%$ & $72.4 \%$ & $73.5 \%$ \\
\hline
\end{tabular}

The totals are not the same for the different breakdowns because the sample includes individuals that did not answer properly the questions that are used to construct the informality variable.

*If the alternative definition of skilled (some college or more) is used, the skill rate reduces to $19 \%$ in 2010 for the nontradable sector and almost $14 \%$ for tradable products.

Source: Author's calculations using data from the Mexican Population and Household Censuses for 2000 and 2010. The sample includes employed individuals aged 25-66.

Considering the skill composition of the tradable and nontradable sectors, it is important to note that both sectors exhibit a similar composition. Approximately $62 \%$ of the individuals in the sample were skilled in 2000, and this share increased to $72 \%$ in 2010 . These figures reflect the educational improvements that Mexico has experienced.When an alternative definition of skilled individuals (some college or more) is used, the structure differs between the tradable and nontradable sectors, being the nontradable sector the one with the highest share of skilled people (19\% in 2010), while the tradable sector showed a rate of $14 \%$ for this same year.

As Table 3 shows, the skill composition of the formal and informal sectors is consistent with the stylized facts of the informal sector as the formal sector has a higher proportion of skilled individuals (86\% in 2010) than the informal sector $(63 \%)$. 
TABLE 3. SKILL VS. INFORMALITY STRUCTURE IN MAS

2000-2010

\begin{tabular}{|c|c|c|c|c|}
\hline & \multicolumn{2}{|c|}{2000} & \multicolumn{2}{|c|}{2010} \\
\hline & Formal & Informal & Formal & Informal \\
\hline Unskilled & $2,186,739$ & $4,272,047$ & $1,575,570$ & $4,292,257$ \\
\hline Skilled & $6,783,000$ & $4,763,972$ & $9,421,980$ & $7,431,319$ \\
\hline Skill rate & $75.6 \%$ & $52.7 \%$ & $85.7 \%$ & $63.4 \%$ \\
\hline
\end{tabular}

Source: Author's calculations using data from the Mexican Population and Household Censuses for 2000 and 2010. The sample includes employed individuals aged 25-66.

When the technological intensity of the tradable sector is taken into account, as can be seen in Table 4, it is important to note that in 2000 , more than half of tradable employment was in the low-technology sector. Between that year and 2010, this proportion exhibited a slight reduction in favor of the medium-high technology group, which increased its share from $24 \%$ to $27 \%$.

Analyzing the skill composition of each technological intensity group (Table 4), as expected, the medium-high technology group is the one that exhibits the highest proportion of skilled people (85\% in 2010), while the other two groups show similar shares (around 70\%).

TABLE 4. SKILL VS. TECHNOLOGICAL INTENSITY OF THE TRADABLE SECTOR IN MAS 2000-2010

\begin{tabular}{|c|c|c|c|c|c|c|c|c|}
\hline & \multicolumn{4}{|c|}{2000} & \multicolumn{4}{|c|}{2010} \\
\hline & Unskilled & Skilled & Total & Skill rate & Unskilled & Skilled & Total & Skill rate \\
\hline Low technology & 955,259 & $1,352,504$ & $2,307,763$ & $58.6 \%$ & 668,775 & $1,473,056$ & $2,141,831$ & $68.8 \%$ \\
\hline Medium-low technology & 325,884 & 484,297 & 810,181 & $59.8 \%$ & 237,696 & 592,519 & 830,215 & $71.4 \%$ \\
\hline Medium-high technology & 272,263 & 730,748 & $1,003,011$ & $72.9 \%$ & 166,065 & 907,406 & $1,073,471$ & $84.5 \%$ \\
\hline Total & $1,553,406$ & $2,567,549$ & $4,120,955$ & & $1,072,536$ & $2,972,981$ & $4,045,517$ & \\
\hline
\end{tabular}

Source: Author's calculations using data from the Mexican Population and Household Censuses for 2000 and 2010. The sample includes employed individuals aged 25-66. 


\section{Results}

\subsection{The local multiplier}

The results for the local multiplier in Mexico between 2000 and 2010, as Table 5 shows, range from 2.56 to 3.91. That is, when one job in the tradable sector is created, between 2 and 4 employments are created in the nontradable sector stemming fromthe increasing demand of such products, mainly services.

Considering that the MA of Valle de Mexico concentrates more than $30 \%$ of tradable employment and more than $35 \%$ of nontradable employment in 2000 , the same regressions were performed excluding this MA. Results indicate a much lower multiplier of between 0.81 and 1.44. This figure is consistent with what Moretti and Thulin (2013) obtain for Sweden when they exclude Stockholm from their sample.

TABLE 5. ESTIMATES OF THE LOCAL MULTIPLIER OF TRADABLE EMPLOYMENT OVER NONTRADABLE EMPLOYMENT

\begin{tabular}{|c|c|c|c|c|c|c|}
\hline \multirow[b]{2}{*}{$\begin{array}{l}\text { Dependent variable: Change in } \\
\text { nontradable employment }\end{array}$} & \multicolumn{3}{|c|}{ Whole sample } & \multicolumn{3}{|c|}{ Excluding Valle de Mexico } \\
\hline & OLS & IV1 & IV2 & OLS & IV1 & IV2 \\
\hline \multirow[t]{2}{*}{ Change in tradable employment } & $2.56^{* * * *}$ & $3.52 * * *$ & $3.91 * * *$ & $1.44 * * *$ & 0.61 & $0.81 * *$ \\
\hline & $(0.47)$ & $(1.14)$ & $(1.22)$ & $(0.30)$ & $(0.74)$ & $(0.33)$ \\
\hline \multirow[t]{2}{*}{ Nontradable employment in 2000} & $0.34 * * *$ & $0.38 * * *$ & $0.39 * * *$ & $0.44 * * *$ & $0.44^{* * *}$ & $0.44 * * *$ \\
\hline & $(0.02)$ & $(0.05)$ & $(0.05)$ & $(0.03)$ & $(0.03)$ & $(0.03)$ \\
\hline $\mathrm{N}$ & 58 & 58 & 58 & 57 & 57 & 57 \\
\hline Prob $>F$ & 0.000 & 0.000 & 0.000 & 0.000 & 0.000 & 0.000 \\
\hline $\mathrm{R}^{2}$ & 0.97 & 0.96 & 0.96 & 0.95 & 0.94 & 0.94 \\
\hline
\end{tabular}

Source:Author's calculations using data from the Mexican Population and Household Censuses for 2000 and 2010.

The equation was estimated with an intercept, but these terms are not included in the table for simplicity.

Standard errors are in parenthesis.

* Significant at the 10 percent level.

** Significant at the 5 percent level.

*** Significant at the 1 percent level.

The Stock \& Yogo test for weak instrument was performed for both IVs and the hypothesis that they are weak instruments is rejected. The IV that exhibits a lower minimum eigenvalue is IV2.

Another important factor to consider is the convergence coefficient, which is robust across regressions and indicates divergence between the MAs in terms of nontradable employment growth. That is, the cities with the higher level of nontradable employment tend to grow more in this same sector. This result contrasts with what is found in studies for the tradable sector, as in most of them convergence is observed in terms of industrial growth. Considering the increasing 
role of the services sectors, these results contribute to the explanation of why there are still important differences in terms of employment level and wealth between the different MAs of the country.

In order to test the predictions of the model regarding the effects of demand shocks in the tradable sectors over other subgroups of the tradable sector, equation 4.2 was estimated. The results, shown in Table 6, indicate that the multiplier is much lower in the OLS specification and furthermore, not significant in the IV estimates. These results are consistent with the idea that tradable firms experience higher labor costs due to the demand shock in other tradable sectors. Hence, the labor multiplier should be lower than the one for the nontradable sector and could even be non-significant or negative, depending on the importance of agglomeration economies.Additionally, the convergence term in this case is negative, indicating that tradable employment growth is higher in MAs that had lower levels of tradable employment.

\section{TABLE 6. ESTIMATES OF THE LOCAL MULTIPLIER OF TRADABLE EMPLOYMENT OVER TRADABLE EMPLOYMENT}

\begin{tabular}{cccc}
\hline $\begin{array}{c}\text { Dependent variable: Change in a subsample of } \\
\text { tradable employment (subsample 1) }\end{array}$ & OLS & IV1 & IV2 \\
\hline Change in tradable employment (subsample 2) & $0.74^{* * *}$ & -0.58 & -0.57 \\
& $(0.21)$ & $(0.66)$ & $(0.63)$ \\
Tradable employment in 2000 & -0.03 & $-0.17^{*}$ & $-0.17^{*}$ \\
$\mathrm{~N}$ & $(0.03)$ & $(0.09)$ & $(0.09)$ \\
Prob>0 & 58 & 58 & 58 \\
$\mathrm{R}^{2}$ & 0 & 0.06 & 0.06 \\
\hline \hline
\end{tabular}

\footnotetext{
Source: Author's calculations using data from the Mexican Population and Household Censuses for 2000 and 2010.

The equation was estimated with an intercept, but these terms are not included in the table for simplicity.

Standard errors are in parenthesis.

* Significant at the 10 percent level.

** Significant at the 5 percent level.

*** Significant at the 1 percent level.

The Stock \& Yogo test for weak instruments was performed for both IVs and the hypothesis that they are weak instruments is rejected in the case of IV1 but not in the case of IV2.
}

\subsection{Local multipliers and informality}

Analyzing whether formal or informal tradable employment generate more non-tradable jobs, Table 7 shows that in specifications that include Valle de Mexico, only the multiplier for tradable formal jobs is significant and even of a much largermagnitude than the average 
multiplier (Table 5) in all specifications while the informal sector appears not to affect nontradable jobs. However, once Valle de Mexico is excluded, the informal multiplier is significant and even higher than the one for the formal sector.That is, informal tradable employment has a multiplier effect in MAs different from Valle de Mexico.

TABLE 7. ESTIMATES OF THE LOCAL MULTIPLIERS

OF TRADABLE FORMAL AND INFORMAL EMPLOYMENT OVER NONTRADABLE EMPLOYMENT

\begin{tabular}{|c|c|c|c|c|c|c|}
\hline \multirow{4}{*}{$\begin{array}{l}\text { Dependent variable: Change in } \\
\text { nontradable employment } \\
\text { Change in tradable formal } \\
\text { employment }\end{array}$} & \multicolumn{3}{|c|}{ Whole sample } & \multicolumn{3}{|c|}{ Excluding Valle de Mexico } \\
\hline & OLS & IV1 & IV2 & OLS & IV1 & IV2 \\
\hline & $2.66 * * *$ & $3.98 * * *$ & $4.20 * * *$ & $1.21 * * *$ & 0.17 & $1.66^{* * *}$ \\
\hline & $(0.7)$ & (1.4) & $(1.1)$ & $(0.3)$ & $(2.2)$ & $(0.6)$ \\
\hline \multirow{2}{*}{$\begin{array}{l}\text { Change in tradableinformal } \\
\text { employment }\end{array}$} & 2.44 & 5.55 & $4.90 *$ & $2.98 * * *$ & $6.20 * *$ & $3.06 * * *$ \\
\hline & $(2.1)$ & $(4.7)$ & $(2.8)$ & $(0.8)$ & $(3.0)$ & $(1.1)$ \\
\hline \multirow[t]{2}{*}{ Nontradable employment in 2000} & $0.34 * * *$ & $0.39^{* * *}$ & $0.40^{* * *}$ & $0.43^{* * *}$ & $0.43^{* * * *}$ & $0.43 * * *$ \\
\hline & $(0.0)$ & $(0.1)$ & $(0.1)$ & $(0.0)$ & $(0.0)$ & $(0.0)$ \\
\hline 4 & 58 & 58 & 58 & 57 & 57 & 57 \\
\hline Prob $>F$ & 0.000 & 0.000 & 0.000 & 0.000 & 0.000 & 0.000 \\
\hline $\mathrm{R}^{2}$ & 0.97 & - & - & 0.94 & - & - \\
\hline
\end{tabular}

Source:Author's calculations using data from the Mexican Population and Household Censuses for 2000 and 2010.

The equation was estimated with an intercept, but these terms are not included in the table for simplicity.

Standard errors are in parenthesis.

* Significant at the 10 percent level.

** Significant at the 5 percent level.

$* * *$ Significant at the 1 percent level.

The Stock \& Yogo test for weak instruments was performed for both IVs and the hypothesis that they are weak instruments is rejected in the case of IV1 but not in the case of IV2 for the whole sample. In the case of the sample that excludes Valle de Mexico, the opposite is observed.

Addressing the important question regarding the quality of indirect jobs created by tradable employment, which is the main contribution of this study, the multipliers for both nontradable formal and informal employment were calculated. Results are shown in Table 8 and the parameters obtained for the whole sample are similar (around 2). In a seemingly unrelated regression (SUR), the Chow test indicated that it is not possible to reject the hypothesis that the parameters for these two sectors are equal. These results are also highly consistent with the multiplier for the whole sample (approximately 3). 
TABLE 8. ESTIMATES OF THE LOCAL MULTIPLIER

FOR NONTRADABLE FORMAL AND INFORMAL EMPLOYMENT

\begin{tabular}{|c|c|c|c|c|c|c|}
\hline & \multicolumn{6}{|c|}{ Dependent variable: Change in nontradable employment } \\
\hline & \multicolumn{3}{|c|}{ Formal } & \multicolumn{3}{|c|}{ Informal } \\
\hline Whole sample & OLS-SUR & IV1 & IV2 & OLS-SUR & IV1 & IV2 \\
\hline Change in tradable employment & $\begin{array}{c}1.36 * * * \\
(0.21)\end{array}$ & $\begin{array}{l}1.78 * * \\
(0.45)\end{array}$ & $\begin{array}{c}2.11^{* * * *} \\
(0.38)\end{array}$ & $\begin{array}{c}1.25 * * * \\
(0.26)\end{array}$ & $\begin{array}{c}1.98 * * \\
(0.78)\end{array}$ & $\begin{array}{c}2.84 * * * \\
(0.90)\end{array}$ \\
\hline \multicolumn{7}{|l|}{ Excluding Valle de Mexico } \\
\hline Change in tradable employment & $\begin{array}{c}0.78^{* * * *} \\
(0.11) \\
58\end{array}$ & $\begin{array}{c}0.51 \\
(0.49) \\
58\end{array}$ & $\begin{array}{c}0.39 \\
(0.59) \\
58\end{array}$ & $\begin{array}{c}0.61 * * * \\
(0.16) \\
57\end{array}$ & $\begin{array}{c}0.55 \\
(0.34) \\
57\end{array}$ & $\begin{array}{c}0.53 \\
(0.37) \\
57\end{array}$ \\
\hline Prob $>F$ & 0.000 & 0.000 & 0.000 & 0.000 & 0.000 & 0.000 \\
\hline Chow test parameters & \multicolumn{3}{|c|}{ Prob $>$ chi $2=0.5035$} & & & \\
\hline
\end{tabular}

Source:Author's calculations using data from the Mexican Population and Household Censuses for 2000 and 2010.

The equation was estimated with an intercept, but these terms are not included in the table for simplicity.

Standard errors are in parenthesis.

* Significant at the 10 percent level.

** Significant at the 5 percent level.

*** Significant at the 1 percent level.

The Stock \& Yogo test for weak instrument was performed for both IVs and the hypothesis that they are weak instruments is rejected in the case of the whole sample; the IV that exhibits a lower minimum eigenvalue is IV2. In the case of the sample that excludes Valle de Mexico the hypothesis of weak instruments can't be rejected for any of the IVs.

\subsection{Local multipliers and skills}

Considering the skill composition of the tradable sector, local multipliers for both skilled and unskilled workers were calculated (Table 9). Although the magnitude is a little higher for skilled jobs, it is not possible to reject the hypothesis that both multipliers are equal. This indicates that under our definition of skilled (9 years or schooling or more), these two groups don't differ in terms of indirect jobs creation. Similar results, but with lower magnitudes are observed when we exclude Valle de Mexico from the sample.

As mentioned before, an alternative definition of skilled was used in order to test the robustness of these results, considering skilled people as those who have some college or more (Table 10). In this case, the effects for the skilled group increase significantly, while the effects for the unskilled group reduce and the hypothesis of equal multipliers is rejected. These results are in line with the conceptual framework as people with college have better wages and can generate higher increases in nontradable demand and thus have a greater capability to indirectly create jobs in this sector. 
TABLE 9. ESTIMATES OF THE LOCAL MULTIPLIER FOR NONTRADABLE EMPLOYMENT BY SKILL LEVEL

\begin{tabular}{lccc}
\hline \hline $\begin{array}{l}\text { Dependent variable: Change in } \\
\text { nontradable employment }\end{array}$ & & & \\
Whole sample & & & \\
& OLS & IV1 & IV2 \\
\cline { 2 - 4 } Skilled & $2.89^{* * *}$ & $4.42^{* * *}$ & $4.56^{* * *}$ \\
& $(0.61)$ & $(0.59)$ & $(0.91)$ \\
Unskilled & $1.75^{* *}$ & $4.15^{* * *}$ & $4.48^{* * *}$ \\
& $(0.71)$ & $(1.57)$ & $(1.43)$ \\
$\mathrm{N}$ & 58 & 58 & 58 \\
Excluding Valle de Mexico & & & \\
Skilled & $1.25^{* * *}$ & 10.43 & $2.76^{*}$ \\
& $(0.40)$ & $(42.8)$ & $(1.52)$ \\
Unskilled & $1.68^{* * *}$ & 10.06 & $3.04 * *$ \\
& $(0.44)$ & $(36.4)$ & $(1.54)$ \\
$\mathrm{N}$ & 57 & 57 & 57 \\
\hline \hline
\end{tabular}

Source:Author's calculations using data from the Mexican Population and Household Censuses for 2000 and 2010.

Standard errors are in parenthesis.

* Significant at the 10 percent level.

** Significant at the 5 percent level.

*** Significant at the 1 percent level.

The Stock \& Yogo test for weak instrument was performed for both IVs and the hypothesis that they are weak instruments is rejected in the case of the whole sample. In the case of the sample that excludes Valle de Mexico, for IV1 the hypothesis of weak instruments can't be rejected. 
TABLE 10. ESTIMATES USING THE ALTERNATIVE DEFINITION OF SKILLED (SOME COLLEGE OR MORE)

\begin{tabular}{lccc}
\hline \hline $\begin{array}{l}\text { Dependent variable: Change in } \\
\text { nontradable employment }\end{array}$ & & & \\
Whole sample & & & IV1 \\
& OLS & $6.44^{* * *}$ & $10.90^{* * *}$ \\
Skilled & $9.15^{* * *}$ & $(2.2)$ & $(2.0)$ \\
& $(2.5)$ & $2.24^{* *}$ & 1.04 \\
Unskilled & $1.02^{* *}$ & $(1.0)$ & $(0.7)$ \\
& $(0.5)$ & 0.000 & 0.000 \\
Prob>F & 0.000 & 58 & 58 \\
$\mathrm{~N}$ & 58 & & \\
Excluding Valle de Mexico & & -13.46 & 3.43 \\
Skilled & $4.15^{* *}$ & $(28.7)$ & $(2.9)$ \\
& $(1.6)$ & 0.44 & $1.09 * *$ \\
Unskilled & $1.06^{* *}$ & $(1.9)$ & $(0.5)$ \\
& $(0.4)$ & 57 & 57 \\
$\mathrm{~N}$ & 57 & & \\
\hline \hline
\end{tabular}

\footnotetext{
Source:Author's calculations using data from the Mexican Population and Household Censuses for 2000 and 2010.

Standard errors are in parenthesis.

* Significant at the 10 percent level.

** Significant at the 5 percent level.

*** Significant at the 1 percent level.

The Stock \& Yogo test for weak instrument was performed for both IVs and the hypothesis that they are weak instruments is rejected for both IV1 and IV2 in the case of the whole sample.

In the case of the sample excluding Valle de Mexico, the hypothesis of weak instruments couldn't be rejected in the case of IV1 but it was rejected in the case of IV2.
}

\subsection{Technological intensity}

In order to analyze what kind of industries of the tradable sector had greater effects over non-tradable job indirect creation, three technological intensity groups were considered: low technology, medium-low technology and medium-high technology (see Appendix 2 for the structure of these groups). Estimates by technological intensity are presented in Table 11. Results show that the medium-low technology group is the one that exhibits the highest multiplier over nontradable employment (between 6 and 7), while the low-technology group is the one that generates less nontradable jobs. When the analysis is extended to consider formal and informal nontradable jobs, results indicate that the medium-low technology sector has a higher effect over informal employment with non-significant multipliers for other technological intensity groups. Formal jobs show a similar pattern than total nontradable jobs, with significant multipliers for medium-high technology industries. 
TABLE 11. ESTIMATES OF THE LOCAL MULTIPLIER

BY TECHNOLOGICAL INTENSITY OF TRADABLE PRODUCTS

\begin{tabular}{lccccccccc}
\hline \hline & \multicolumn{3}{c}{ Total nontradable } & \multicolumn{3}{c}{ Nontradable formal } & \multicolumn{3}{c}{ Nontradable informal } \\
\hline Whole sample & OLS & IV1 & IV2 & OLS & IV1 & IV2 & OLS & IV1 & IV2 \\
Low-technology & $1.58^{* * *}$ & 1.81 & 1.73 & $0.91^{* * *}$ & 0.99 & $0.96^{*}$ & 0.41 & 0.55 & 0.33 \\
& $(0.5)$ & $(4.1)$ & $(1.1)$ & $(0.2)$ & $(2.1)$ & $(0.5)$ & $(0.3)$ & $(2.6)$ & $(0.6)$ \\
Medium-low & $6.01^{* * *}$ & -13.47 & $7.16^{*}$ & $2.33^{* * *}$ & -6.43 & 2.56 & $4.28^{* * *}$ & -9.33 & $5.33^{* *}$ \\
& $(1.8)$ & $(18.4)$ & $(4.3)$ & $(0.8)$ & $(7.1)$ & $(1.8)$ & $(1.1)$ & $(15.7)$ & $(2.3)$ \\
Medium-high & $2.06^{* * *}$ & 10.45 & $2.67 *$ & $1.36^{* * *}$ & $5.20^{* *}$ & $1.76^{* *}$ & 0.66 & 6.39 & 0.87 \\
& $(0.7)$ & $(7.3)$ & $(1.5)$ & $(0.4)$ & $(2.6)$ & $(0.7)$ & $(0.4)$ & $(6.5)$ & $(0.8)$
\end{tabular}

Excluding Valle de

Mexico

\begin{tabular}{lccccccccc} 
Low-technology & $2.20 * * *$ & $2.07 * *$ & $2.33^{* * *}$ & $1.19 * * *$ & $1.24 * * *$ & $1.15 * * *$ & $0.67 * * *$ & -0.2 & 0.73 \\
\multirow{3}{*}{ Medium-low } & $(0.4)$ & $(0.8)$ & $(0.9)$ & $(0.2)$ & $(0.2)$ & $(0.2)$ & $(0.3)$ & $(1.7)$ & $(0.6)$ \\
& 1.93 & 1.75 & -4.44 & 0.53 & 0.72 & -0.51 & $1.91 * *$ & 9.99 & -1.6 \\
\multirow{3}{*}{ Medium-high } & $(1.2)$ & $(15.3)$ & $(3.9)$ & $(0.4)$ & $(1.7)$ & $(0.8)$ & $(0.9)$ & $(17.7)$ & $(1.9)$ \\
& $0.90^{*}$ & 1.01 & $3.43 * *$ & $0.68 * * *$ & 0.9 & $1.19 * * *$ & 0.17 & -3.12 & $1.49 * *$ \\
& $(0.5)$ & $(5.9)$ & $(1.5)$ & $(0.2)$ & $(0.6)$ & $(0.3)$ & $(0.4)$ & $(6.1)$ & $(0.7)$ \\
\hline \hline
\end{tabular}

Source:Author's calculations using data from the Mexican Population and Household Censuses for 2000 and 2010.

Standard errors are in parenthesis.

* Significant at the 10 percent level.

** Significant at the 5 percent level.

*** Significant at the 1 percent level.

The Stock \& Yogo test for weak instrument was performed for both IVs and the hypothesis that they are weak instruments is rejected

for IV2, but not for IV1 in both the cases of the whole sample and excluding Valle de Mexico.

Excluding Valle de Mexico both low-technology and medium-high technology sectors have significant multipliers while there is no effect of the medium-low group.

In order to further analyze these results and test their robustness, a regression including technological-skill groups was estimated. ${ }^{21}$ Results show that skilled workers from the three technological intensity groups have significant multipliers, being low-technology and mediumlow technology the ones that exhibit the highest values (almost 5). However, in the case of unskilled individuals, only the ones who work in the medium-high technology group have an effect over nontradable job creation.

\footnotetext{
${ }^{21}$ Results are not shown here but are available upon request. In this case the hypothesis of weak instrument couldn't be rejected for any IV specification so the results analyzed come from the OLS regression.
} 


\subsection{Asymmetries}

As mentioned before, the multipliers are important not just in terms of employment creation when a positive shock occurs, but also when a firm closes and job losses are expected. Therefore, the following formulation was tested in order to assess whether negative shocks have larger multipliers.

$$
N_{c, t}^{N T}-N_{c, t-s}^{N T}=\alpha+\beta N_{c, t-s}^{N T}+\gamma\left(N_{c, t}^{T}-N_{c, t-s}^{T}\right)+d\left(N_{c, t}^{T}-N_{c, t-s}^{T}\right)+\varepsilon_{c, t}
$$

Where:

$d=$ dummy variable equal to 1 when $\left(N_{c, t}^{T}-N_{c, t-s}^{T}\right)<0$

The result from this specification, shown in Table 12, indicate that when Valle de Mexico is considered there are asymmetries in the effects, with job losses having a much higher multiplier (triple) than tradable jobs creation. However, in the sample that excludes this MA, negative shocks do not exhibit a different multiplier than positive ones.

TABLE 12. ESTIMATES OF ASYMMETRIES IN THE MULTIPLIERS

\begin{tabular}{|c|c|c|}
\hline Dependent variable: Change in nontradable employment & Whole sample & Excluding Valle de Mexico \\
\hline & OLS & OLS \\
\hline \multirow[t]{2}{*}{ Change in tradable employment (baseline-positive) } & $1.03^{* *}$ & $1.16^{* * *}$ \\
\hline & $(0.4)$ & $(0.4)$ \\
\hline \multirow[t]{2}{*}{ Change in tradable employment (dummy negative) } & $3.63 * * *$ & 1.06 \\
\hline & $(1.3)$ & $(0.8)$ \\
\hline \multirow[t]{2}{*}{ Nontradable employment in 2000} & $0.42 * * *$ & $0.45^{* * *}$ \\
\hline & $(0.0)$ & $(0.0)$ \\
\hline \multirow[t]{2}{*}{ Constant } & 5448.49 & -1397.74 \\
\hline & -3711.47 & -2530.64 \\
\hline $\mathrm{N}$ & 58 & 57 \\
\hline $\mathrm{P}$ & 0 & 0 \\
\hline $\mathrm{R}^{2}$ & 0.98 & 0.95 \\
\hline
\end{tabular}

Source:Author's calculations using data from the Mexican Population and Household Censuses for 2000 and 2010.

Standard errors are in parenthesis.

* Significant at the 10 percent level.

** Significant at the 5 percent level.

*** Significant at the 1 percent level. 


\section{Discussion}

Every time a city attracts new firms in the tradable sector, there is an indirect jobs creation stemming from the higher demand for nontradable goods. These multipliers are important for regional development policy as local governments grant incentives for investments and having a measure of the expected job multiplier can contribute to assess the appropriateness of these efforts and to better target them.

In the case of Mexico, considering that approximately $60 \%$ of employment occurs in the informal sector, it is also important to assess the quality of jobs created as a result of demand shocks in the tradable sector.

This paper analyzed local multipliers in the case of Mexico between 2000 and 2010, emphasizing the role of the informal sector in both the tradable and nontradable sectors. It also studied this process considering different skill levels and technological intensities with the purpose of identifying which tradable jobs have a higher capability for creating nontradable employment. In order to address the problems generated by unobserved shocks to nontradable employment that also affect tradable employment, group-specific IVs were used.

The multipliers observed indicate that for every new tradable job, approximately three nontradable jobs are created. This result is high compared to what Moretti (2010) finds for the U.S., but is highly consistent with what Moretti and Thulin (2013) observe for Sweden. ${ }^{22}$ Another finding was that the effects are asymmetric, as negative shocks have a much larger effect than positive shocks.

Considering the quality of these jobs, the employment structure appears to reproduce itself as new jobs created in the tradable sector (which has a lower informality rate than the nontradable sector) generate formal and informal jobs in the same proportion. This is not a desirable outcome considering the low tax collection and vulnerability to labor market shocks associated to informality.

Regarding the skill structure of tradable jobs, defining skilled individuals as those with nine or more years of education, results indicate that there is no difference in terms of jobs creation between skilled and unskilled. However, using an alternative definition of skilled (some college

\footnotetext{
${ }^{22}$ The multiplier reduces significantly when Valle de Mexico is excluded from the sample, similar to what Moretti and Thulin (2013) find for Sweden when Stcokholm is excluded.
} 
or more), the multiplier is at least three times higher for skilled workers than for the unskilled ones.

Additionally, taking into consideration the technological intensity of tradable employment, it was found that medium-high technology jobs have higher effects on nontradable formal employment while medium-low technology sectors have a greater capability for informal nontradable jobs creation.

This paper is a first approach for Mexico's local multipliers and the analysis should be extended in different dimensions. First of all, it is important to include cluster analysis as in Delgado et al. (2005) in order to have a more precise definition of the tradable, nontradable and resource-based sectors, which can lead to more detailed conclusions. Second, even though the administrative definition of MAs has the advantage of being exogenous to the data used in this analysis, different geographic arrangements should be tested in order to assess the sensitiveness of these results. For example, different local labor markets can be constructed using observable variables. Third, the use of firm level data, can provide further information as the effect of the establishment of new firms in an MA can be directly analyzed. Finally, considering that the conceptual framework establishes higher demand for non-tradable products as the channel through which the multiplier operates, it is important to analyze consumption patterns in order to better characterize the effects found in this paper.

\section{References}

Alcaraz, C., Chiquiar, D., \& Ramos-Francia, M. (2008). "Diferenciales salariales intersectoriales y el cambio en la composición del empleo urbano de la economía mexicana en 2001-2004."Banco de México. Documentos de Investigación, (2008-06).

Arias, J., Azuara, O., Bernal, P., Heckman, J. J., \& Villarreal, C. (2010). "Policies to promote growth and economic efficiency in Mexico." (No. w16554). NBER.

Banerjee, A. V., and Newman, A. F. (1993). "Occupational choice and the process of development." Journal of political economy, 274-298.

Black, D., McKinnish, T., \& Sanders, S. (2005). "The Economic Impact Of The Coal Boom And Bust." Economic Journal, Royal Economic Society, 115(4): 449-476.

Bonner, C., \& Spooner, D. (2011). "Organizing in the informal economy: a challenge for trade unions."Internationale Politik und Gesellschaft, 2(2011): 87-105. 
Carrington, W. J. (1996). “The Alaskan labor market during the pipeline era." Journal of Political Economy, 186-218.

Cortez, W. W. (2001). "What is behind increasing wage inequality in Mexico?."World Development, 29(11): 1905-1922.

Delgado, M., Porter, M.E., \& Stern, S. (2012). "Clusters, Convergence, and Economic Performance." NBER Working Paper No. 18250.

Esquivel, G., \& Ordaz-Diaz, J. L. (2008). “¿Es la política social una causa de la informalidad en México?.” Ensayos Revista de Economia, 27(1), 1-32.

Fortin, B., Marceau, N., \&Savard, L. (1997). “Taxation, wage controls and the informal sector.” Journal of Public Economics, 66(2): 293-312.

Galiani, S., \& Weinschelbaum, F. (2012). "Modeling informality formally: households and firms." Economic Inquiry, 50(3): 821-838.

Glaeser, E.L. (2008). Cities, Agglomeration, and Spatial Equilibrium, New York, NY: Oxford University Press.

Glaeser, E. L. (2009). "The Death and Life of Cities."Making Cities Work: Prospects and Policies for Urban America, 22: 25-26.

Glaeser, E.L., \&Gottlieb, J.D. (2009). "The Wealth of Cities: Agglomeration Economies and Spatial Equilibrium in the United States," Journal of Economic Literature, American Economic Association, 47(4): 983-1028.

Glaeser, E. L., Kallal, H. D., Scheinkman, J. A., \& Shleifer, A. (1992). “Growth in Cities.” Journal of Political Economy, 100(6): 1126-1152.

Greenstone, M., \& Moretti, E. (2004). "Bidding for Industrial Plants: Does Winning a 'Million Dollar Plant'Increase Welfare?”, mimeo, MIT, January.

Greenstone, M., Hornbeck, R., \& Moretti, E. (2010). "Identifying Agglomeration Spillovers: Evidence from Winners and Losers of Large Plant Openings.”Journal of Political Economy, 118(3).

ILO (2012). Measuring Informality: a new statistical manual on the informal sector and informal employment. Retrieved from www.ilo.org

INEGI (1999). 1999Economic Census. Retrieved from www.inegi.org.mx

INEGI (2000). 2000 Population and Housing Census. Retrieved from www.inegi.org.mx

INEGI (2009). 2009Economic Census. Retrieved from www.inegi.org.mx

INEGI (2010). 2010 Population and Housing Census. Retrieved from www.inegi.org.mx

INEGI (2012). Informal Employment in Mexico. Press release 449/12.

Jensen, J. B., Kletzer, L. G., Bernstein, J., \& Feenstra, R. C. (2005, January). "Tradable Services: Understanding the Scope and Impact of Services Offshoring [with Comments and Discussion]." In Brookings trade forum (75-133). The Brookings Institution. 
Levy, S. (2008). Good intentions, bad outcomes: Social policy, informality, and economic growth in Mexico. Brookings Institution Press.

Loayza, N., \& Sugawara, N. (2005). "El sector informal en México. Hechos y explicaciones fundamentales." El Trimestre Económico, 76(304): 887-920.

Maloney, W. F. (1999). "Does informality imply segmentation in urban labor markets? Evidence from sectoral transitions in Mexico." The World Bank Economic Review, 13(2): 275-302.

Maloney, W. F. (2004). “Informality revisited.” World development, 32(7): 1159-1178.

Moretti, E. (2010). “Local Multipliers”, American Economic Review: Papers \& Proceedings, 100: 1-7.

Moretti, E. (2011), "Local Labor Markets", in Ashenfelter, O. and Card. D.E. (Eds.), Handbook of Labor Economics. North Holland.

Moretti, E., \& Thulin, P. (2013). "Local multipliers and human capital in the United States and Sweden." Industrial and Corporate Change,22 (1): 339-362. doi: 10.1093/icc/dts051

Perry, G., Maloney, W. F. , Arias, O. S., Fajnzylber, P.,Mason, A.,\& SaavedraJ.(2007).Informality: Exit and exclusion. Washington, DC: World Bank Publications

Porter, M. (2003). “The economic performance of regions.”Regional studies, 37(6-7): 545-546.

Rauch, J. E. (1991). "Modelling the informal sector formally."Journal of Development Economics, 35(1), $33-47$.

Ray, D. (1998). Development economics. Princeton University Press.

Roback, J. (1982). "Wages, Rents, and the Quality of Life.” Journal of Political Economy, 90 (6): 12571278.

Rosen, S. (1979). "Wage-based indexes of urban quality of life."Current issues in urban economics, 3.

Romer, C., \& Bernstein, J. (2009). The job impact of the American recovery and reinvestment plan.

Spence, M., \& Hlatshwayo, S. (2012). "The evolving structure of the American economy and the employment challenge."Comparative Economic Studies, 54(4): 703-738.

Straub, S. (2005). "Informal sector: the credit market channel." Journal of Development Economics, 78(2): 299-321. 


\section{Appendix 1MAs considered in the analysis}

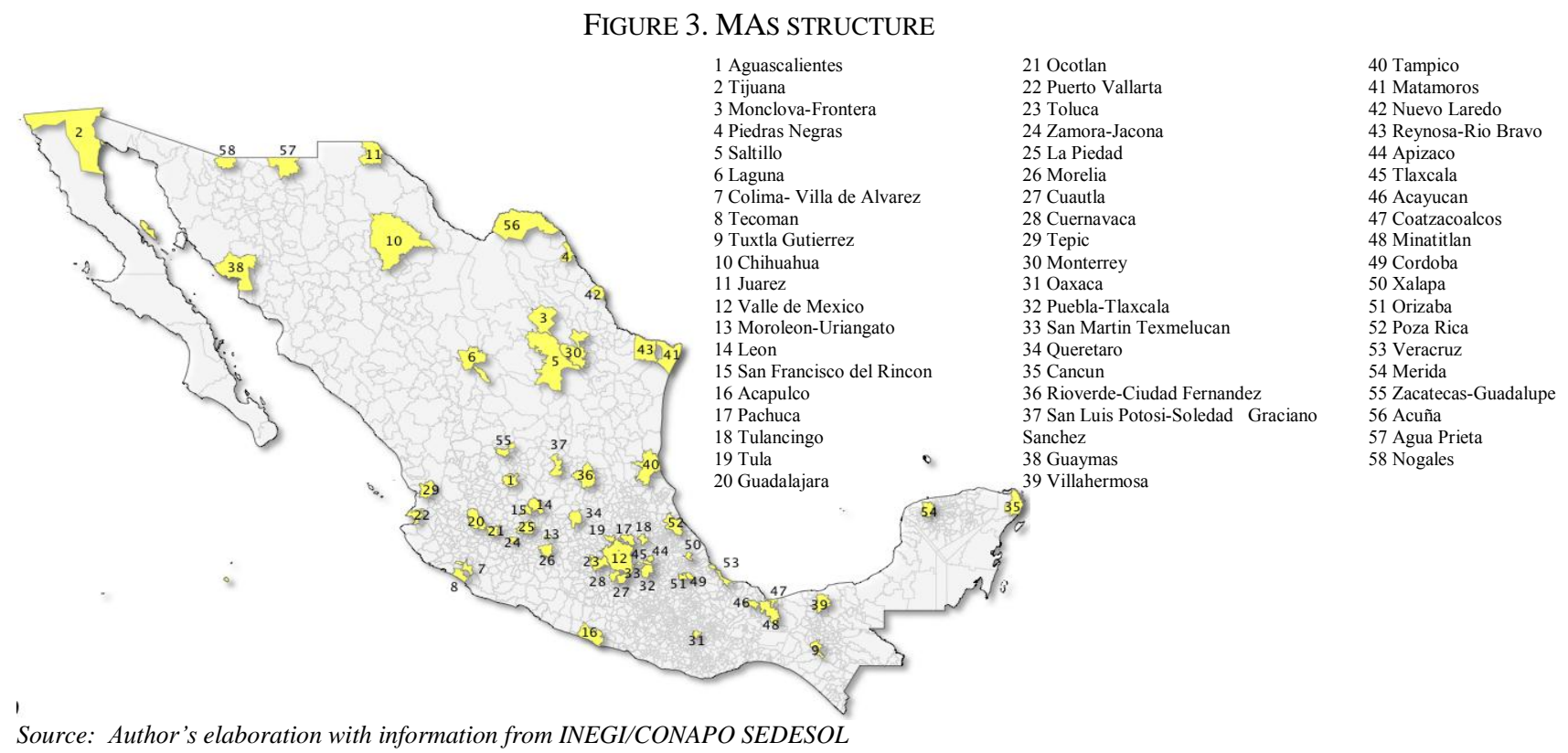

\section{Appendix 2 OECD classification by technological intensity (ISIC rev. 3)}

This classification is based on the analysis of Research and Development (R\&D) expenses, as well as the production of twelve members of the OECD during 1991-1999. The ISIC REV. 3 and input-output matrices are used.

The classification of manufacturing sectors in high-technology, medium-high technology, mediumlow technology and low technology was made after sorting the different industries according to their average for 1991-1999. There were also considered: i) temporal stability, that is, that for adjacent years industries classified under the highest categories had more intensity than the ones classified in the lowest categories. ii) country median stability which means that industries classified to the higher categories have a higher median intensity than those in lower categories.

Even though this classification considers four categories, in the case of high-technology only a handful of sectors appear in this category. Therefore, the two higher technology groups were considered as one: 
TABLE 13. PRODUCTS CLASSIFICATION BY TECHNOLOGICAL INTENSITY

\begin{tabular}{lll}
\hline \multicolumn{1}{c}{ Low intensity } & \multicolumn{1}{c}{ Medium-low intensity } & \multicolumn{1}{c}{ Medium-high intensity } \\
\hline $\begin{array}{l}\text { Food, beverages and tobacco } \\
\text { Textiles }\end{array}$ & $\begin{array}{l}\text { Petroleum and coal products } \\
\text { manufacturing }\end{array}$ & $\begin{array}{l}\text { Machinery and equipment } \\
\text { Transportation equipment }\end{array}$ \\
Apparel & Plastic and rubber & Computers and electronics \\
Weather and footwear & Non-metallic mineral products & Electric apparatus \\
Paper & Primary metal manufacturing and metal & Chemical products \\
Printing & products & \\
Furniture and mattresses & & \\
Other industries & & \\
Source: Author's elaboration with information from the OECD. &
\end{tabular}

Source: Author's elaboration with information from the OECD. 